\title{
Heterogeneity and Clustering of Housing Demand: Case Study
}

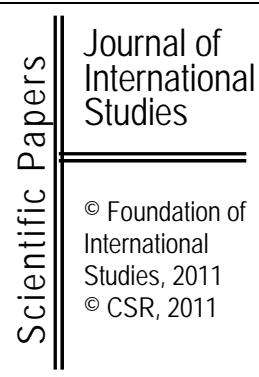

PhD Michał Głuszak

PhD Bartłomiej Marona

Department of Real Estate and Investment Economics

Cracow University of Economics

gluszakm@uek.krakow.pl

\begin{abstract}
The paper discusses major approaches to housing demand segmentation. The aim of the article is to evaluate the relations between (i) sociodemographic and (ii) preference-based segmentation.

Second part of the article discusses the results of two studies of housing demand conducted in Poland in recent years. We compare usefulness of two approaches in terms of residential investments analysis, and housing policy debate. Additionally, in the article author studies correspondence between preferences of potential house buyers and their socio-economical status.
\end{abstract}

Submitted: August, 2011 $1^{\text {st }}$ revision: September, 2011

Accepted: October, 2011

Keywords: housing demand, segmentation, correspondence analysis, cluster analysis

JEL classification: C38, R21.

\section{Introduction}

Although some orthodox economist would not agree (Stigler and Becker, 1977), recent research has shown that neither housing preferences nor housing demand are homogeneous (Tu and Goldfinch, 1996). Heterogeneous consumers can be grouped based upon similarities they share: basic characteristics, needs, preferences, attitudes.

In terms of housing demand, a market segment should meet three basic criteria: (1) being distinct from other segments (different segments have different needs), (2) being homogeneous within the segment (exhibits common needs); (3) being responsive to same market stimulus. Marketing theory has developed several strategies, methods and techniques to deal with heterogeneous consumers. Four basic necessary conditions for successful market segmentation are: (1) clear identification of the segment, (2) measurability of its effective size, (3) accessibility through promotional efforts, and (4) appropriateness to the policies and resources of the supply side of the market.

There are basically four demand segmentation approaches, that can also be adopted to housing market. These can be based on (i) behavioral (ii) demographic, (iii) psychographic/lifestyle, and (iv) geographical differences.

The paper discusses two major approaches to housing demand segmentation. The aim of the article is to discuss differences between (i) socio-demographic and (ii) preference-based segmentation (which can be considered to be a special case of behavioral segmentation) of housing demand. The goal is not exclusively academic. As market segmentation is often used 
by housing investors (developers) to discover consumer niches, we believe that results of the study have some practical applications.

Empirical part of the article discusses the results of two studies of housing demand conducted in Poland in recent years. We compare usefulness of two approaches in terms of residential investments analysis, and housing policy debate. Additionally, in the article we study correspondence between preferences of potential house buyers and their socioeconomical status.

\section{Data and methods}

While there are many important and interesting theoretical issues related to housing market segmentation, the main interest of this review is in empirical applications. As limited article space precludes an exhaustive review, we focus on two examples in more detail.

Segmentation study can be based on revealed preference data (actual housing decisions) or stated preference data (hypothetical choices of potential housing investors). Discussion on advantages and disadvantages of these two sources of data can be found in Earnhart (1998).

In our comparative study we use stated preference data. To be specific, we study the results of two questionnaire-based research of housing demand.

In the first study we analyze simple socio-demographic segmentation - performed with simple cross tabulation techniques. The first study reflects housing demand and stated preferences in five major polish metropolitan areas - Warsaw, Krakow, Poznan, Wroclaw, TriCity. At the time of the study each of these metropolitan housing market in Poland shared similar problems and perspectives:

- inelastic supply caused by bureaucratic planning procedures;

- increasing demand driven recently by low interest rates and expectations of potential buyers about future prices level and country development, after joining European Union;

- varity of housing products offered on the market: from exclusive and newly renovated apartments in the city centre, through middle-class houses estates in the outskirts of the city to socialist legacy of immense blocks of flats.

Second study focuses on housing demand in Krakow. The analysis was conducted in three phases:

(i) preliminary exploration: in the first phase overall preference profile of potential house-buyers was under scrutiny. Additionally, demographic and economic characteristics of respondents were examined.

(ii) housing market segmentation: in the second phase hierarchical cluster analysis was performed to group potential buyers into groups with similar preferences.

(iii) exploring correspondence: in the last phase relation between preference based segmentation and socio-demographic characteristics of potential house-buyers was examined. Exploration was performed with the help of multiple correspondence analysis - a technique used to identify and represent underlying structures in nominal categorical data (for detailed discussion see: Greenacre, 1993). 


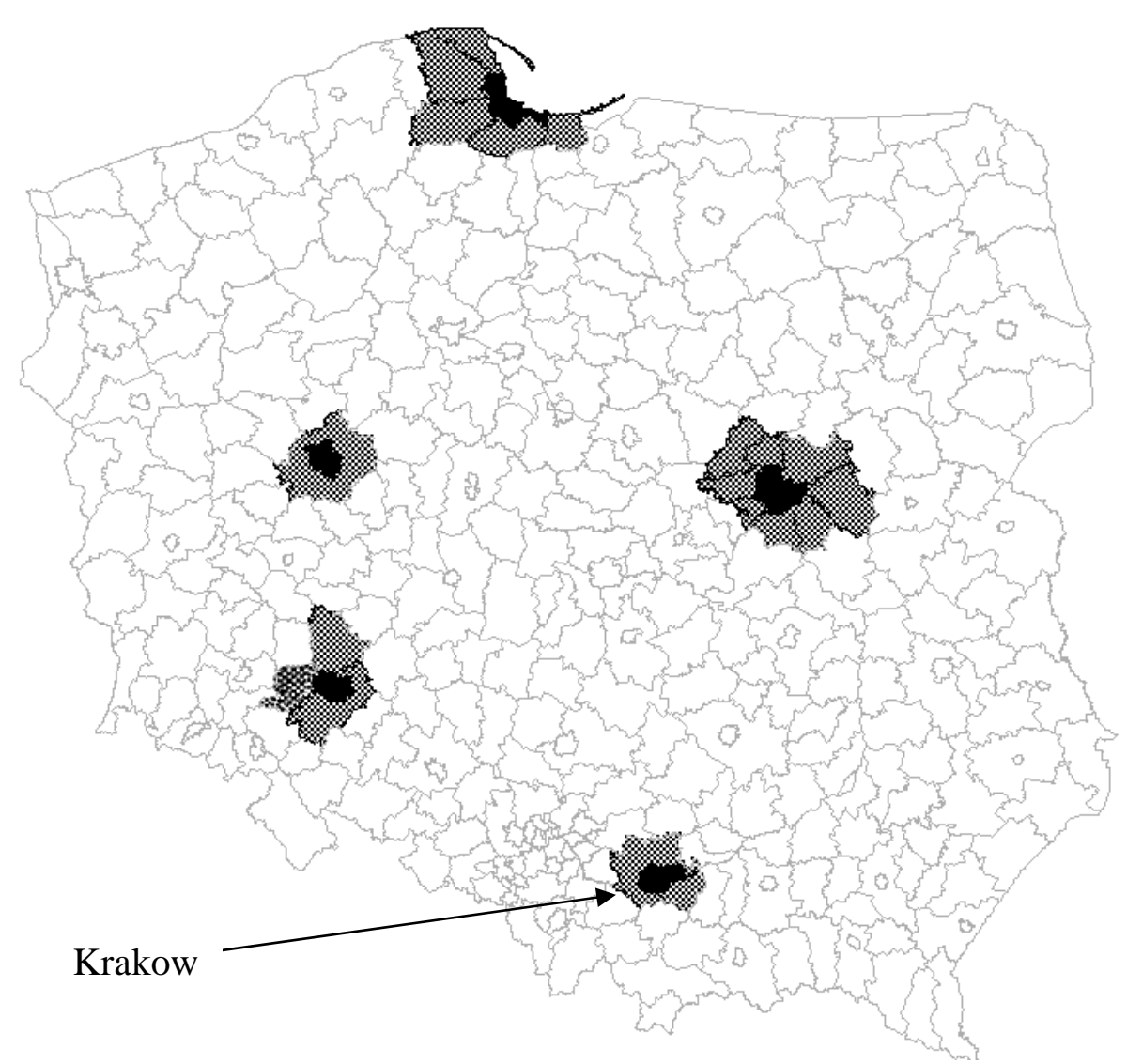

Figure 1. Major housing markets in Poland

In the research cluster analysis and multiple correspondence analysis are used complementary to make profiles of preferences and their relation to socio-economical status of potential buyers more readable - as suggested by Lebart (1994). The comprehensive, and up to date, review housing demand research methodology (also multivariate techniques like cluster analysis) can be found in Jansen et al. (2010).

\section{Socio-demographic market segmentation - Polish case}

In the research we use state preference survey data from "Housing market in Poland. Demand and buyers preferences", conducted by Millward Brown SMG/KRC in late 2007. Each survey examined hypothetical housing decisions of 1500 households in five major polish metropolitan areas - Warsaw, Krakow, Poznan, Wroclaw, and TriCity. The survey used probability sampling procedure. The time of the survey coincided with the peak of the housing market cycle.

Based on household characteristics we can perform simple socio-demographic segmentation of potential house buyers. The results of segmentation are shown on a mosaic plot (Figure 2). 


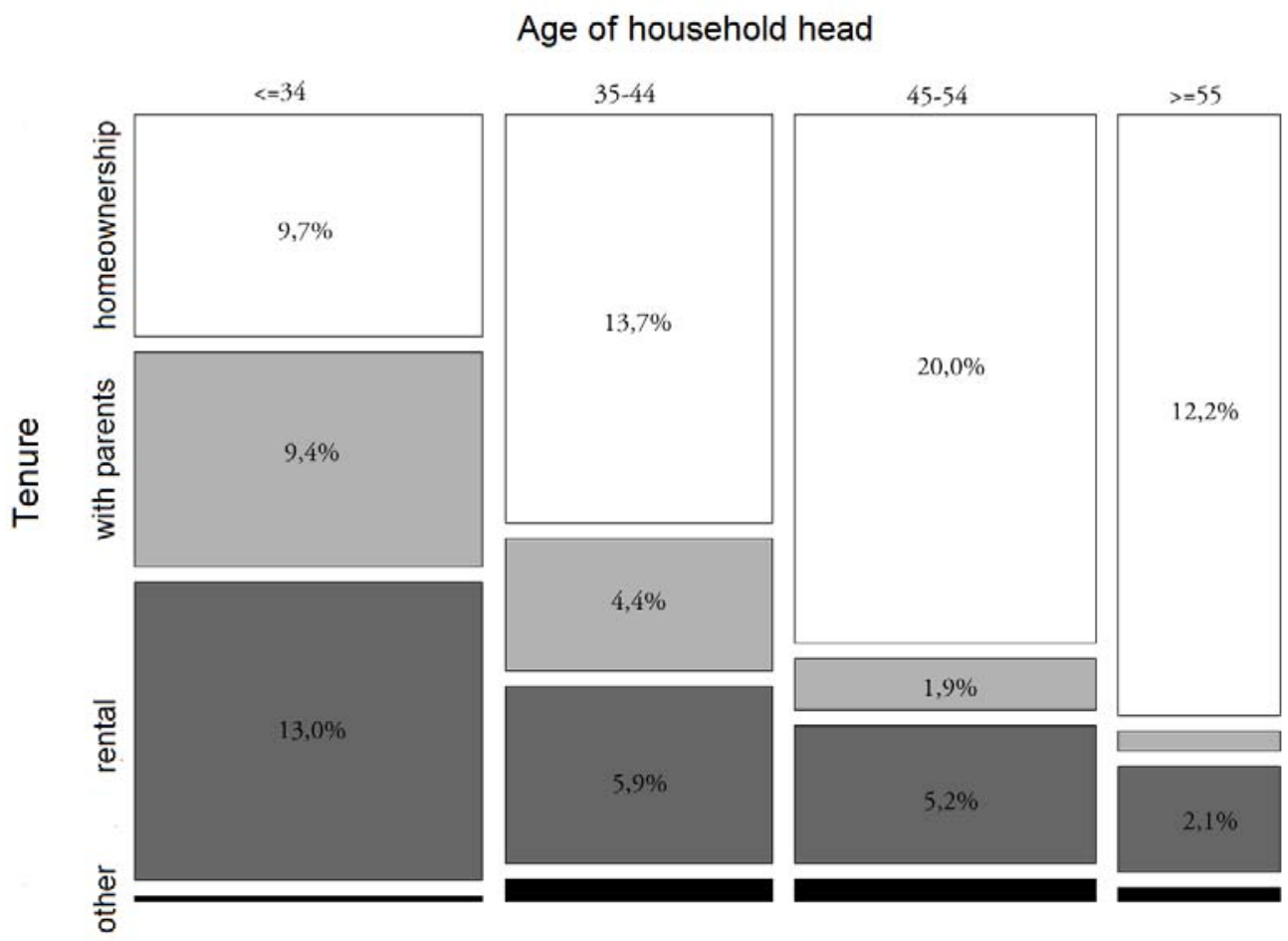

Figure 2. Tenure-age based housing demand segmentation

Source: authors' own based on "Housing market in Poland. Demand and buyers preferences" survey data

It can be seen that there are several important segments of housebuyers. Major segment of housing demand (33,7\% of a sample) is related to mature household, that are homeowners. Their activity on a housing market is usually driven by housing mobility (they move to a larger, and more comfortable dwellings). Second important group are young households (usually without children) still living with their parents or renters $(22,4 \%)$. Although we will not test it here we can believe that these two groups have different housing needs, and therefore distinct housing preferences.

Simple segmentation can be performed using other sociodemographic characteristics of households.

Table 1. Lifecycle based housing demand segmentation

\begin{tabular}{|c|c|c|c|c|}
\hline \multirow{2}{*}{\multicolumn{2}{|c|}{ Household type }} & \multicolumn{3}{|c|}{ Age of household's head (years) } \\
\hline & & \multirow{2}{*}{$\begin{array}{r}25-35 \\
346\end{array}$} & \multirow{2}{*}{$\begin{array}{r}36-45 \\
90\end{array}$} & \multirow{2}{*}{$\begin{array}{r}46-65 \\
172\end{array}$} \\
\hline \multirow{2}{*}{ Type 1. Household without children } & $\mathrm{N}$ & & & \\
\hline & $\% \mathrm{~N}$ & $22,47 \%$ & $5,84 \%$ & $11,17 \%$ \\
\hline \multirow{2}{*}{ Type 2 Household with adolescent children } & $\mathrm{N}$ & 200 & 264 & 468 \\
\hline & $\% \mathrm{~N}$ & $12,99 \%$ & $17,14 \%$ & $30,39 \%$ \\
\hline \multirow{2}{*}{ Type 3 Household with adult children } & $\mathrm{N}$ & 0 & 46 & 360 \\
\hline & $\% \mathrm{~N}$ & $0,00 \%$ & $2,99 \%$ & $23,38 \%$ \\
\hline
\end{tabular}

Source: as in Figure 2.

Cross-tabulating household type (to simplify we identified three types) and household 
age we arrive at 9 segments, with somewhat different lifecycle. Again three major groups can be identified. First segment are mature households with adolescent children $(37,5 \%$ of a sample). Second consist of young households without children (22,5\%). Third segment are household with adult children (23,4\%).

To conclude, demographic segmentation is relatively simple and easy to conduct. Usefulness of these approach is rather limited though, because homogeneity (in terms of preferences, traits, and other important factors) in each segment is rather vague.

\section{Preference based market segmentation - Krakow case}

Our analysis is conducted on survey data gathered from potential house-buyers in Krakow by real estate internet portal Dominium.pl. Researchers collected data during 4 successive "Housing Exhibitions" that took place in Krakow in June, September, October and November of 2003 and at "Housing Fair" held in June 2003. The survey was conducted among households searching for a new housing (dwelling or house), and used non-probability sampling procedure. During the research, 210 face-to-face interviews were conducted. In spite of non-probability the structure of the respondents (at least when income, age, and household size are concerned) was similar to other research, that used probability sampling (for example "Housing market in Poland. Demand and buyers preferences" survey). We can conclude that it provides some justification for the representativeness of the sample.

In general, the most important features for potential buyers were price and location. The majority of respondents declared that this two attributes have decisive or significant impact on their housing decision. The neighbourhood of a building had somewhat smaller weight. Only $25 \%$ of respondents considered it an attribute of decisive importance. Other apartment features like house arrangement, safety features and additional facilities were fairly important. The housing investor and the architecture of a building had comparatively smallest impact on housing decision (but significant in sense of absolute values).

The conclusion, after examining overall profile of consumer characteristics, is clear. In general, the respondents tend to overrate importance of house features, which seems to be an effect of the mode of questioning used in the questionnaire. This conclusion is consistent with opinions articulated in the literature. For instance, Nelson and Rabianski suggest that direct questioning methods extort a more rational perceptual framework (Nelson, Rabianski, 1988).

To group consumers into homogeneous preference segments, hierarchical cluster analysis was performed. The furthest neighbour method of agglomeration was used. The city block distance (the Manhattan distance) as a measure of distance between respondents was chosen. Variables were standardized, in order to limit scale influence on the results. 
Table 2. Variables and scales used in hierarchical clustering

\begin{tabular}{|l|l|}
\hline Variable & Scale \\
\hline $\begin{array}{l}\text { localization } \\
\text { investor } \\
\text { price } \\
\text { rooms arrangement } \\
\text { architecture } \\
\text { neighborhood }\end{array}$ & $\begin{array}{l}0 \text { - unimportant, } \\
1 \text { - average importance, } \\
2 \text {-considerable importance, } \\
3 \text { - decisive }\end{array}$ \\
\hline safety features & $\begin{array}{l}0-5 \text { (number of options from the list: alarm, monitoring, } \\
\text { security agency, anti-burglary doors, fence) }\end{array}$ \\
\hline additional features & $\begin{array}{l}0-5 \text { (number of options from the list: additional telephone } \\
\text { line, door phone, internet, cable TV) }\end{array}$ \\
\hline other facilities & $\begin{array}{l}0-5 \text { (number of options from the list: balcony, cellar, dries } \\
\text { room n the building, children playground, additional storage } \\
\text { room) }\end{array}$ \\
\hline
\end{tabular}

Source: authors’ own based on Dominium.pl survey data.

Through the classification process, six clusters were revealed. Each cluster was described ex post by the distinct characteristics of individual involved, and assigned with a mnemonic label. Salient characteristics of the clusters are listed below.

Cluster 1 "Hesitating" (98 respondents, 47\% of the total sample): The largest consumer segment includes people with imprecise, intermediate preferences. No specific house attribute seems to have particular importance to typical representative of the cluster. The choice of housing district is also unclear. They want to live in Krowodrza but considerable percentage expresses interest in City Centre as well as in Podgorze.

Cluster 2 "Pragmatic" (19 respondents, 9\%): Preferences profile of this group members has precise and practical character. House attributes they value the most are localization, price and safety (no other group values the two latter attributes of future apartment so much). The least important house features is developer (housing construction firm) and the architecture of the building/house (the feature of less material character). They tend to prefer Krowodrza and Podgorze. They value City Centre less than the other groups (from the practical point of view living in the proximity of Old Town can be very uncomfortable. Considerable percent of the "Pragmatics", especially in comparison to other clusters, expressed interest in Nowa Huta.

Cluster 3 "Demanding" (37 respondents, 15\%): This cluster includes people with high profile and fixed preferences. Practically all house attributes are considered important. Additionally, cluster members value localization, architecture and neighborhood more than any other cluster. Room arrangement is also important. Features they put less emphasis to are safety, additional features and facilities. Their preference towards housing location are precise (they usually name only one district).

Cluster 4 "Cautious" (40 respondents, 19\%): They make up a numerous group. They value developer of the future house the most (most likely preferring trustworthy firms with documented history of previous housing constructions) as well as localization. They value safety features and facilities. The least important are architecture and neighborhood, as well as the functional arrangement of an apartment.

Cluster 5 "Undemanding" (11 respondents, 5\%): For members of this small segment the most important attribute is the price of an apartment. Following features have little importance (especially in comparison to other clusters). They value localization less than other groups (their preference towards city district are unclear - members of the group often 
indicated two or three areas).

Cluster 6 "Nouveaux riche" (9 respondents, 5\%): The "nouveaux riche" are quite similar in preferences to "demanding" cluster. The crucial difference lies in declared importance of the apartment price. Responses of the cluster members indicate that price plays little role in decision process (particularly in comparison to the significance of other attributes). Moreover, "Nouveaux riche" value the most those house attributes that are perceived as associated with prestige: the arrangement of apartment, architecture and surrounding of the building. They favour additional apartment features ( 2 line, internet, cable TV, etc.).

In the next stage we explore relation between cluster membership and socioeconomical status. The aim is to discover whether homogenous preference cluster differ in terms of maximum planned expenditure on future housing.

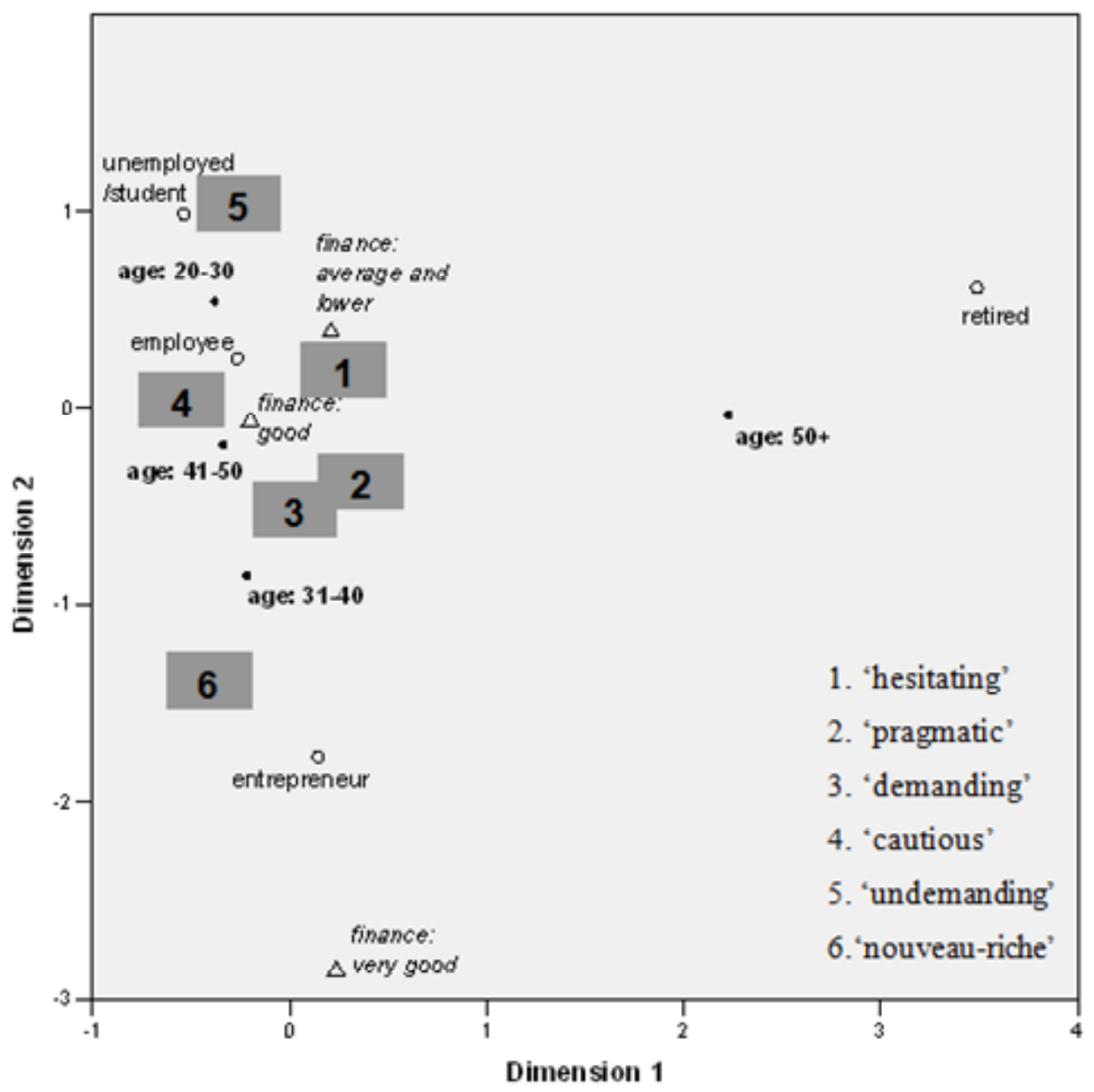

Graph 3. Multi Correspondence Analysis of consumer segments and their social and economic characteristics

Source: As in table 2.

To analyze relations between housing preferences and basic socio-economic factors we applied correspondence analysis. To describe a relation between cluster membership and socio-demographic features, fictitious modal element was described. Fictitious representatives of each cluster possess the most salient characteristics. Analysis of the willingness to pay (WTP) shows that clusters significantly differ when we compare maximum expenditures on 
future house. On average "nouveaux-riche" cluster members wanted to spend more than any other group (PLN 200.000, at the time of the survey). On average "demanding" cluster representatives planned to spend less, but still more than other groups. Clusters of "hesitating”, "pragmatic" and "cautious" planned comparatively similar expenditures (on average approximately 150.000). On the other hand, "Undemanding" cluster members planned to buy inexpensive flats (on average, for no more than PLN 100.000).

Cluster 1 "Hesitating” - modal element: This type of preference can be characteristic for persons with distinct socio-economical status. His financial status is avarege or good. He is interested in purchasing inexpensive, moderate size lodgings. Housing purchase purpose can be various: migration to Cracow, buying first house or investment. On average, he planned to spend less then PLN 150,000 on future house.

Cluster 2 "Pragmatic" - modal element: Preferences seem not to correspond with demographic characteristics of the respondents. Financial status of "pragmatic" is slightly better than in case of "hesitating" type. "Pragmatic" is usually aged 30-50. On average, he planned to spend maximum of PLN 150,000 on future apartment.

Cluster 3 "Demanding" - modal element: He is 30-50 years old. The purchase of apartment is for him the investment of capital. He is interested in buying large (60 to 80 sq. meters) apartment. He wants to exchange currently owned apartment for larger or treats purchase as a long-term investment. On average, he was able to spend about PLN 180.000 to purchase a new house.

Cluster 4 "Cautious" - modal element: He can be 20-30 or 40-50 years old. In the latter case, he wants to exchange currently owned flat for a bigger one. On average, he planned to spend about PLN 150,000 on future apartment.

Cluster 5 "Undemanding" - modal element: The typical representative of this group does not work, or is a student. He is 20-30 years old. He intends to buy a first house or (and) migrated to Cracow in order to find job. His financial status is unclear, he may also depend on his parents or credit. He searches for inexpensive flat (on average maximum expenditure on future house was only PLN 100.000)

Cluster 6 "Nouveaux riche" - modal element: Model representative of this cluster entrepreneur, aged 30-40. He usually intends to exchange apartment for larger, alternatively treats housing purchase as an investment. He is interested in large apartments (more than 80 sq. meters). On average, he planned to spend about PLN 200,000 on future apartment (more than any other group).

\section{Conclusions}

The overall outcomes of this research have drawn out an implication in regard to use of selected tools of housing demand segmentation. As can be seen from two case studies both sociodemographic and preference-based segmentation can prove to be a valuable tool when planning housing investments and housing policy.

Firstly, when socio-demographic segmentation is concerned it should be noted however that homogenous (at least in terms of basic characteristics) households, do not have similar preference. Enriching segmentation model by adding psychographic and lifestyle indicators could prove more valuable in explaining preference patterns (for discussion see also: Nelson and Rabianski, 1988).

Secondly, when direct stated-preference segmentation is concerned, joint use of cluster and correspondence analysis provided interesting results - extorting six homogenous groups of potential housebuyers. Although the research was exploratory, we should indicate that simple demographic characteristics, do not explain preference variance (attribution to each of discovered clusters). 


\section{References}

Afifi, A., Clark, V. (1992), Computer-Aided Multivariate Analysis, Chapman \& Hill, London.

Earnhart, D. (1998), Combining Revealed and Stated Data to Examine Decisions of Housing Location: Discrete-Choice Hedonic and Conjoint Analysis, University of Kansas, Working Paper.

Greenacre, M. (1993), Correspondence Analysis in Practice, Academic Press, London.

Jansen, S., Coolen, H., Goetgeluk, R. (eds.) (2010), Measurement and Analysis of Housing Preference and Choice, Springer, London.

Lebart, L. (1994), Complementary use of Correspondence Analysis and Cluster Analysis in: M. Greenacre, J. Blasius (eds.), Correspondence Analysis in the Social Sciences, Academic Press, London.

Nelson, T., Rabianski, J. (1988), Consumer Preferences in Housing Market Analysis: An Application of Multidimensional Scaling Techniques, AREUEA Journal, Vol. 16, No. 2.

Stigler, G., Becker, G. (1977), De Gustibus Non Est Disputandum, American Economic Review, Vol. 67.

Tu, Y., Goldfinch, J. (1996), A Two-stage Housing Choice Forecasting Model, Urban Studies, Vol. 33. 